Original Research Paper

\title{
Probabilistic Seismic Hazard Deaggregation for Karaj City (Iran)
}

\author{
Hadi Jarahi \\ Department of Tunnel, Harazrah Consulting Engineers Group, Tehran, Iran
}

Article history

Received: 06-05-2016

Revised: 10-06-2016

Accepted: 16-06-2016

Email: hadijarahi@gmail.com

\begin{abstract}
In this study the results of PSHA deaggregation for 5\%-damped $0.2,0.5,2$ and $4 \mathrm{~s}$ spectral accelerations, corresponding to Mean Return Periods (MRPs) of 50 and $475 \mathrm{yr}$ for Karaj city was presented. The aim of this paper is to quantify the dominant events that have the most contribution on ground-motion exceedance from the above mentioned hazard levels. The scenario earthquakes are characterized by bins of Magnitude (M) and source-to-site distance (R). The results reveal that for Karaj city, the hazard is mainly controlled by near active fault.
\end{abstract}

Keywords: Deaggregation, Spectral Accelerations, Karaj City, Seismic Hazard Component

\section{Introduction}

Iran is one of the most seismic active countries in the world. During the last several decades several thousand people lost their lives, sever economic impacts and social damages were experienced. For example, during the 1990 Rudbar earthquake $(\mathrm{Mw}=$ 7.3) in northwest Iran, more than 40,000 people lost their lives, more than 500,000 became homeless, nearly 100,000 buildings were destroyed, three cities and 700 villages were demolished. Iran has been host to a long series of large damaging earthquakes, many of them occurring within the 20th century. There have been roughly 126,000 deaths attributed to 14 earthquakes of magnitude $\sim 7.0$ (one 7.0 earthquake/7yr) and 51 earthquakes of 6.0-6.9 (one/2-yr) that have occurred in Iran since 1900. During this period nine (9) cities were devastated (one city/1 O-yr). Review of the historical seismic data shows that almost every part of the country has been hit by major earthquakes during the last century. Zagros, Alborz and Khorasan seismic regions are among the most seismically active regions of the country.

One of the advantages of PSHA is that it allows computation of the mean annual rate of exceedance at a particular site based on aggregated hazard of all possible range of magnitudes from potential seismic sources, occurring at many different source-to site distances. This integrating nature of PSHA leads to lose the concept of a single event threat for the site (McGuire, 1995). The so-called dominant events
(Bazzurro and Cornell, 1999) or design earthquakes (McGuire, 1995) are required to evaluate many characteristics of the ground motion, such as dynamic time history analysis, duration, nonstationary of motion and critical pulses (Cramer and Petersen, 1996). Design earthquakes can be chosen based on deterministic assumptions, such as the magnitude of the worst historical event reported and its best guessed location derived from known active structures. On the other hand, usually for the common case of a site, highfrequency hazard is dominated by frequent local earthquakes and low-frequency hazard is dominated by large magnitude earthquakes over a wide range of distances, therefore the selection of a unique earthquake scenario does not guarantee an equal seismic protection for the site under analysis (Sousa and Costa, 2009). In order to derive a seismic scenario consistent with the results of PSHA for a site and determine the relative contribution of events to the overall seismic hazard, the concept of deaggregation was introduced. The deaggregation process separates the contributions to the Mean annual Rate of Exceedance (MRE) of a specific ground-motion value at a site due to scenarios of giving magnitude $M$ and distance $\mathrm{R}$ and often $\varepsilon$, the ground motion error term. The $\varepsilon$ value is defined as the number of standard deviations by which the (logarithmic) ground motion generated by a given M-R pair deviates from the median value estimated by a prediction equation (Barani et al., 2009). The seismic hazard deaggregation process has been performed by Bernreuter (1992) for the 
first time and following this study, deaggregation methods and applications were extensively discussed and improved by Chapman (1995; McGuire, 1995; Cramer and Petersen, 1996; Bazzurro and Cornell, 1999; Harmsen et al., 1999; Sokolov, 2000; Harmsen, 2001; Harmsen and Frankel, 2001; Montilla et al., 2002; Halchuk and Adams, 2004), etc. In order to perform deaggregation of seismic hazard for Karaj city, probabilistic seismic hazard assessment is evaluated for the study area (yellow area in Fig. 1). Selecting this area allows to get involved in assessments and calculations all of the elements that could affect the seismicity of Karaj. The city of Karaj with highly dense population (about 5 million people) has not experienced a damaging earthquake since 1830 , although it is located in an active seismic zone and surrounded by active faults with evidence of historical destructive earthquakes. The major aim of this study is the deaggregation of the hazard results in terms of magnitude, distance and epsilon, to investigate earthquake occurrences that have the most contribution to the resulting ground-motion hazard in Karaj. In this regard, 6 liner seismic sources are delineated in the study region and the quantified hazard values in terms of the Peak Ground Acceleration (PGA) over bedrock, are mapped for 63 and $10 \%$ probabilities of exceedance in
50 years on grid intervals of $0.1^{\circ}$, using the 4 Next Generation Attenuations (NGA). Then, based on obtained results of PSHA, deaggregation of the hazard is performed in terms of magnitude-distance pairs and epsilon for Karaj city.

\section{Tectonic Setting}

The study area covers the Alborz. Along the Alborz and the Central Iran seismotectonic provinces seismicity occur primarily in the upper crust, but some infrequent events occur in the mid-crust of the Alborz, where the South Caspian basin under thrusts the Alborz along the Khazar fault (JICA and CEST, 2000). Despite the relatively high elevation of Alborz Mountains, the Bougure anomaly has very small negative values and the crustal thickness is less than $35 \mathrm{~km}$ along the Caspian coast; therefore, it must be considered as mountains without root whose uplift is due to thrusting of allochthonous masses over each other in a compressional tectonic regime (Dehghani and Makris, 1983). Fault plane solutions of earthquakes in the study region indicate both thrust and strike-slip faulting, though the thrust faulting is prominent (Berberian, 2014; Abdi et al., 2013).

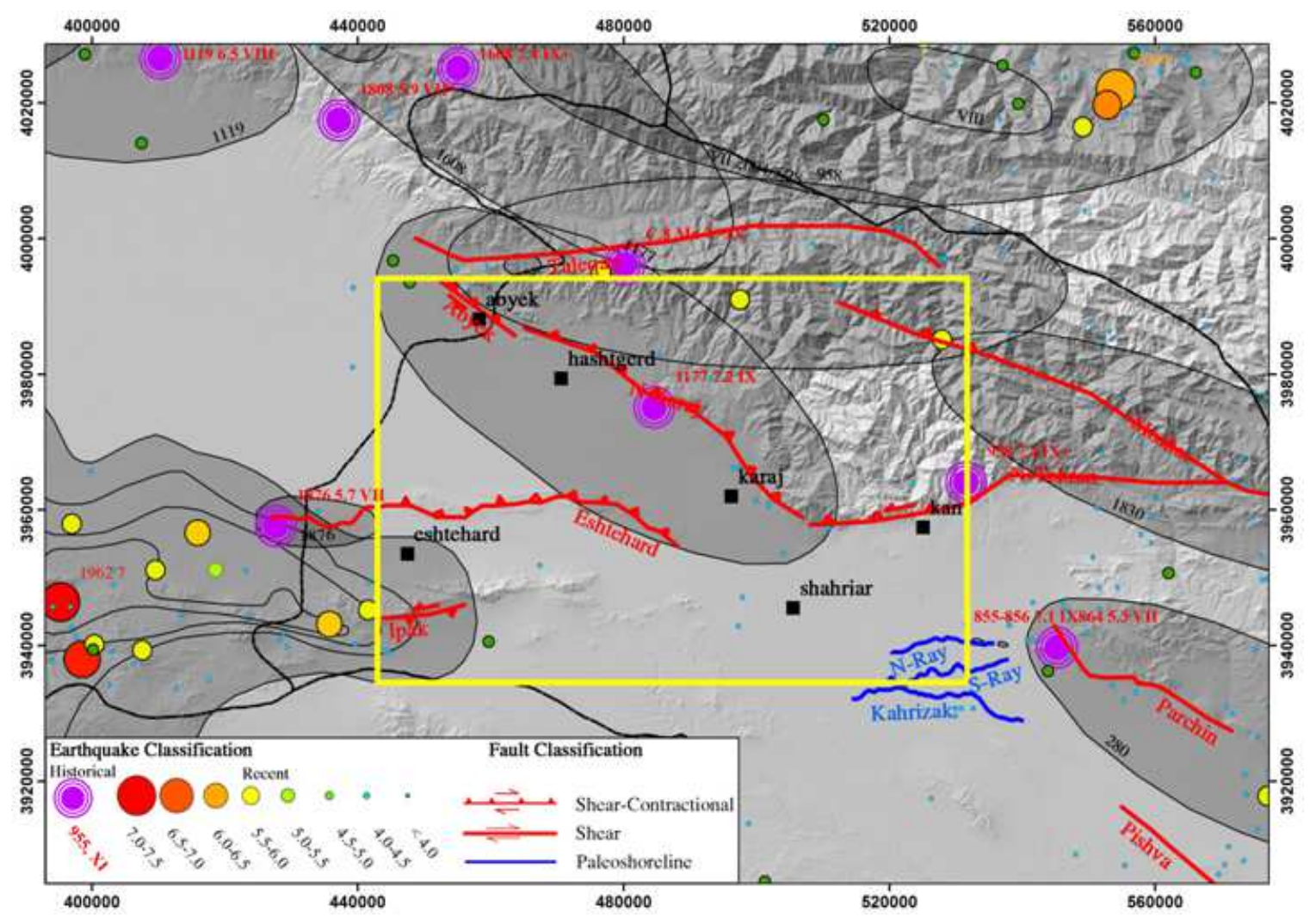

Fig. 1. Map of seismic sources of Karaj region. Elipsioids show the Meizoseismal area of earthquakes 


\section{Probabilistic Seismic Hazard Analysis}

According to traditional methodology of PSHA (Cornell, 1968; Kijko, 2012), at first, potential seismic sources should be delineated and then seismicity parameters in each source will be determined. For regions with insufficient earthquake data, seismicity studies in potential seismic sources using the traditional method brings a noticeable uncertainty into results. To overcome such shortcomings, the traditional method has been modified by Shi et al. (1992) and developed by Ni (2012); therefore, inhomogeneity of seismicity in time and space could properly be regarded. In this study, the modified methodology of PSHA is applied. Three major steps of modified method are (Shabani and Mirzaei, 2007; Kijko, 2012):

- Delineation of seismotectonic provinces and evaluation of seismicity parameters

- Determination of potential seismic sources

- Dividing the interest region into a series of grid points and assessment of seismic hazard for every grid point

Seismotectonic province is defined as an area that under the present-day geodynamic regimes has a comparable tectonic setting and unified seismicity pattern (Ye et al., 1995; Mirzaei et al., 1998). According to Mirzaei et al. (1998), territory of Iran can be divided into five major seismotectonic provinces based on all available geophysical, geological, tectonic and earthquake data. A uniform catalog of earthquakes containing historical and instrumental events covering the period from $400 \mathrm{BC}$ to 2013 is used (Table 1). The earthquake database is mainly compiled from ISC for the modern instrumental time period (1964-2013) and the catalog of earthquakes provided by Ambraseys and Melville (1982) is the basic source of parameters for the historical (before 1900) and early instrumental (19001963) time periods. The catalog of earthquakes has been made uniform using the relationships between Ms and $\mathrm{mb}$ for selected area.

Since we encountered an incomplete earthquake catalog in the study region, the procedures introduced by Kijko (2010), which permit incorporation of magnitude uncertainty to estimate seismicity parameters from incomplete data files, are applied to the uniform catalog of earthquakes for estimating the seismicity parameters. Results of the estimation of seismicity parameters in the selected area are presented in Table 2.

Figure 1 shows potential seismic sources in Karaj region. Further the meizoseismal area of historical events and paleoshoreline trace (Jarahi et al., 2016) are shown. A total of 6 line sources and their corresponding Mmax are chosen. For estimatingMmax, used 4 tentative relationships between fault rapture length and earthquake magnitude (Zare, 1995; Wells and Coppersmith, 1994; Nowroozi, 1985; Ambraseys and Jackson, 1998). Then, by using logic tree (Fig. 2), that was match with tectonic setting of study area, value of Mmax has been weighted and then estimated (Table 3).

Table 1. Event count for 1 Magnitude bins and 10 year bins

\begin{tabular}{|c|c|c|c|c|c|}
\hline \multirow[b]{2}{*}{ Date Range } & \multicolumn{4}{|c|}{ Magnitude Range } & \multirow[b]{2}{*}{ Grand total } \\
\hline & $4-4.9$ & $5-5.9$ & $6-6.9$ & $7-7.7$ & \\
\hline \multicolumn{6}{|l|}{ Historical } \\
\hline (400-1900) & & 6 & 10 & 10 & 26 \\
\hline 1900-1909 & & 1 & & & 1 \\
\hline 1910-1919 & & & & & 0 \\
\hline 1920-1929 & & 1 & & & 1 \\
\hline 1930-1939 & & 9 & & & 9 \\
\hline 1940-1949 & 2 & 1 & & & 3 \\
\hline $1950-1959$ & 5 & 5 & 2 & 3 & 15 \\
\hline $1960-1969$ & 12 & 10 & 3 & 3 & 28 \\
\hline 1970-1979 & 40 & 8 & & & 48 \\
\hline 1980-1989 & 42 & 28 & & & 70 \\
\hline 1990-1999 & 69 & 22 & & & 91 \\
\hline $2000-2009$ & 39 & 9 & & & 48 \\
\hline 2010-2013 & 44 & 4 & 5 & & 53 \\
\hline Grand Total & 253 & 104 & 20 & 16 & 393 \\
\hline
\end{tabular}

Table 2. Estimation of seismicity parameters from recorded earthquakes in the selected area

\begin{tabular}{ll}
\hline Parameter & Value \\
\hline $\mathrm{B}$ & $1.63 \pm 0.07(\mathrm{~b}=0.71 \pm 0.03)$ \\
$\lambda$ & $0.72 \pm 0.04($ forMmin $=4.3)$ \\
Mmax & $7.2 \pm 0.11$ (for SIG (Xmax) $=0.10)$ \\
\hline
\end{tabular}


Table 3. Seismicity Parameters of seismic source of study area. $M_{\max }$ calculated as the percentage weight of every relationship in front of it is inserted. In this process the four empirical relations use an event earthquakes associated with the fault as a factor in determining $\mathrm{M}_{\max }$ is intended

\begin{tabular}{|c|c|c|c|c|c|}
\hline \multirow[b]{2}{*}{ Seismic source } & \multicolumn{5}{|l|}{$\mathrm{M}_{\max }$} \\
\hline & $1(40 \%)$ & $2(20 \%)$ & $3(22 \%)$ & $4(18 \%)$ & Weighted \\
\hline N-Karaj & 6.8 & 7.6 & 6.9 & 6.8 & 7.0 \\
\hline Eshtehard & 6.8 & 7.5 & 6.8 & 6.7 & 6.9 \\
\hline N-Tehran & 7.2 & 7.8 & 7.1 & 7.0 & 7.2 \\
\hline Mosha & 7.0 & 7.7 & 7.0 & 6.9 & 7.1 \\
\hline Abyek & 6.5 & 7.4 & 6.7 & 6.6 & 6.7 \\
\hline Ipak & 7.0 & 7.6 & 7.0 & 6.9 & 7.1 \\
\hline
\end{tabular}

1- Zare (1995); 2- Wells and Coppersmith (1994); 3- Nowroozi (1985); 4- Ambraseys and Jackson (1998)

Mmax

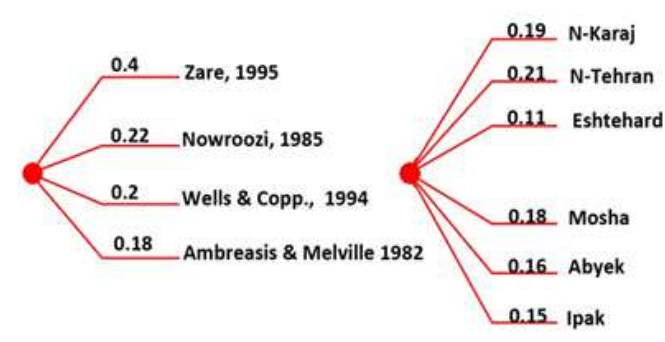

Atention Equation

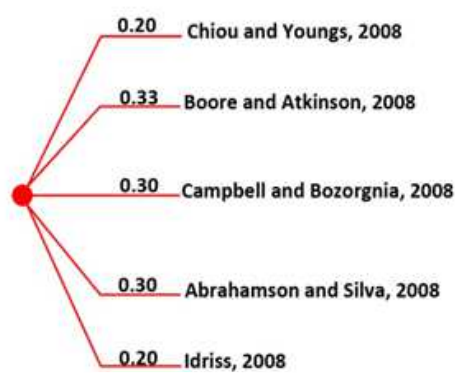

Fig. 2. The logic tree for weighting seismic parameters (Jarahi et al., 2016)

Generally, in seismic hazard analysis, annual rate of earthquakes in active faults is calculated by definite integration on magnitude-frequency relation.

For the hazard analysis the EZ-FRISK program utilized to compute the hazard analysis of this study. The EZ-FRISK program calculates seismic hazard using the standard methodology for seismic hazard analysis mentioned above.

In the regions with high seismic activity, any seismic hazard assessment needs a set of attenuation equations which could appropriately represent the variable parameters of the strong motion in that region. For the Iranian plateau, there is a limited number of reliable strong ground-motion data to perform a specific attenuation relationship, especially in the near-source areas of large earthquakes. For example the Iranian strong-motion data have a total of only 4 recordings for magnitudes greater than 7.0 and distances less than 30 $\mathrm{km}$ (Shoja-Taheri et al., 2010). Due to this reason, applying worldwide attenuation models for similar tectonic environment is appropriate. We have adopted for this study the attenuation relationship for rock (Vs $>$ $750 \mathrm{~m} / \mathrm{s}$ ) developed by Boore and Atkinson NGA model (2008). The NGA project has resulted in the publication of five new ground-motion models to predict PGA, PGV and response spectral ordinates for periods 0.0 up to 10.0 s (Abrahamson and Silva, 2008; Boore and Atkinson, 2008; Campbell and Bozorgnia, 2008; Chiou and Youngs, 2008; Idriss, 2008). The NGA database is one of the largest databases of uniformly processed strong ground-motion recorded in shallow crustal earthquakes in active tectonic regions, including data recorded in the 1978 Tabas and 1990 Manjil earthquake that occurred, respectively, in central-east Iran and Alborz-Azerbaijan Seismotectonic provinces of Iran. Thus, these new equations might also be applied as ground-motion prediction in other parts of the world with the similar tectonic environment, such as the region encompassing the Iranian plateau. Shoja-Taheri et al. (2010) carried out a comprehensive study on comparison of the three NGA equations (Boore and Atkinson, 2008; Campbell and Bozorgnia, 2008; Chiou and Youngs, 2008) as representative of all the NGA models, with the strongmotion data recorded in Iran and concluded that the three NGA models are generally applicable to the presently available Iranian dataset. Shoja-Taheri et al. (2010) also mentioned that the NGA model of Boore and Atkinson (2008) is somewhat more applicable for Iran than the other two models, since some of the details on the near source effects in it (e.g., effects of hanging wall and footwall, distance of the upper part of the fault rupture to the surface and so on) are excluded. Seismic hazard assessment has been performed for a grid of points with $0.1^{\circ}$ interval in longitude and latitude in the study area. PGAs over bedrock, for Mean Return Periods (MRPs) of 50 and $475 \mathrm{yr}$, have been estimated and seismic zoning maps of the Karaj region was determined using EZFRISK computer program (Fig. 3). 

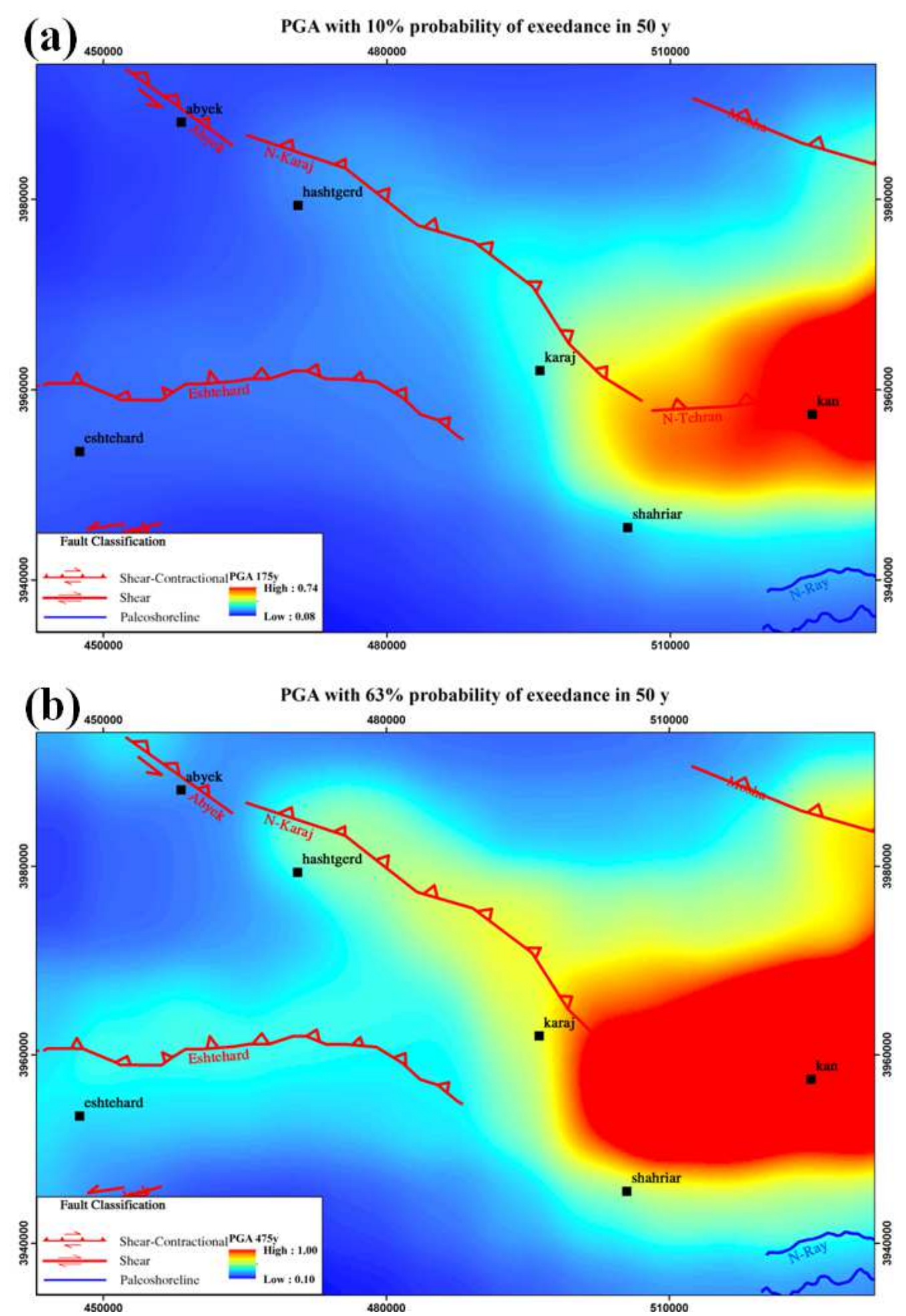

Fig. 3.Probabilistic seismic hazard map of Karaj region for peak horizontal acceleration on firm-rock site conditions for $10 \%$ (a) and $63 \%$ (b) probability of exceedance in $50 \mathrm{yr}$

The results show a good agreement with active faults and seismicity of the region. Sites with the highest level of PGA are mainly adaptable to N-Karaj, N-Tehran,
Mosha, Eshtehard and Abyekfaults. The maximum PGAs at Karaj city are estimated to be 0.36 and $0.22 \mathrm{~g}$ for 475 and 50 yr return periods, respectively. 


\section{Seismic Hazard Deaggregation}

For a specified spectral period and ground motion amplitude, the seismic hazard can be deaggregated to show the contribution to the annual frequency of exceedance by magnitude $(\mathrm{M})$, distance $(\mathrm{R})$ and the deviation parameter in the attenuation equation $(\varepsilon)$. In general, deaggregating the hazard at high amplitudes indicates that large $M$, small $R$ and large $\varepsilon$ contribute most to hazard (these indications are reversed for low amplitudes of shaking). Low frequencies of shaking are usually associated with larger $M$ and larger $R$ than high frequencies. Attenuation equations that show lower dependence on $M$ (or magnitude saturation at high amplitudes) generally show more contribution from lower magnitudes than those with high dependence on $M$ (or no magnitude saturation). Finally, magnitudedependent $\varepsilon$ terms on attenuation equations (where $\varepsilon$ decreases with increasing $M$ ) tend to shift the contribution to lower magnitude values.

EZ-FRISK allows deaggregation by $M, R$ and $\varepsilon$, as well as $M-R$, through plots and printed reports (Halchuk and Adams, 2004). EZ-FRISK code reports the deaggregation results in terms of Probability Density Function (PDF), which is obtained by dividing the Probability Mass Function (PMF) contribution of each bin by the bin's size, thus the PDF representation is independent of the bin's amplitude (Bazzurro and Cornell, 1999). The hazard can be simultaneously deaggregated in different types of bins. EZ-FRISK presents the result of seismic hazard deaggregation in terms of 1-D M, R and 2-D M-R bins. A detailed review of different representations (PDF and PMF) and procedures (1-D, 2-D and 3-D deaggregation, geographical deaggregation in terms of latitude and longitude) can be found in Bazzurro and Cornell (1999). Usually, mean values of $\mathrm{M}$ and $\mathrm{R}$ are reported for identifying the dominant event, because each of them has its advantages and disadvantages. The mean values $(\mathrm{M}$, R) are defined unambiguously and do not depend on the bin size, but they may correspond to a scenario that is not realistic, if there are two or more sources with significant contribution to the hazard.

Figure 4 and 5 (a through d) shows the M-R deaggregation plots of the 5\%-damped linear elastic $\mathrm{S}_{\mathrm{a}}(\mathrm{T})$ values at periods of $0.2,0.5,2$ and $4 \mathrm{~s}$ which correspond to MRPs of 50 and $475 \mathrm{yr}$. The results of computed controlling earthquakes have been summarized in Table 4 . The $50 \mathrm{yrS}_{\mathrm{a}}(0.2 \mathrm{~s})$ hazard for Karaj is controlled by almost nearby earthquakes of moderate magnitude. Larger and more distant events dominate the $S_{a}(4 s)$ value for the same MRP. In particular, scenario earthquakes ranging from a magnitude $\mathrm{M}=5.2$ at $\mathrm{R}=13 \mathrm{~km}$ for $_{\mathrm{a}}(0.2 \mathrm{~s})$, to $\mathrm{a}$ magnitude $M=6.9$ at $R=4 \mathrm{~km}$ for $S_{a}(4.0 \mathrm{~s})$ has been determined to represent the relatively likely ground motion having a $63 \%$ chance of being exceeded in 50 yr. For less probable, extreme ground motions with a $10 \%$ chance of being exceeded in $50 \mathrm{yr}$, the scenario earthquakes ranging from a magnitude $\mathrm{M}=5.0$ at $\mathrm{R}=$ $19 \mathrm{~km}$ for $\mathrm{S}_{\mathrm{a}}(\mathrm{PGA})$, to a magnitude $\mathrm{M}=6.7$ at $\mathrm{R}=4$ $\mathrm{km}$ for $\mathrm{S}_{\mathrm{a}}(4.0 \mathrm{~s})$ are represented as dominant events (Fig. 4 and 5).

Table 4. M-R deaggregation results for $0.2,0.5,2$ and 4 s spectral acceleration values corresponding to MRPs of 50 and 475 year Return Periods (year)

\begin{tabular}{|c|c|c|c|c|}
\hline \multirow[b]{2}{*}{ Period (s) } & \multicolumn{2}{|l|}{50} & \multicolumn{2}{|l|}{475} \\
\hline & Dis. $(\mathrm{km})$ & Mag. & Dis.(km) & Mag. \\
\hline 0.2 & 19.09 & 5.03 & 13.31 & 5.29 \\
\hline 0.5 & 14.42 & 5.41 & 9.44 & 5.91 \\
\hline 2 & 6.3 & 6.54 & 4.94 & 6.73 \\
\hline 4 & 4.38 & 6.75 & 4.65 & 6.9 \\
\hline
\end{tabular}

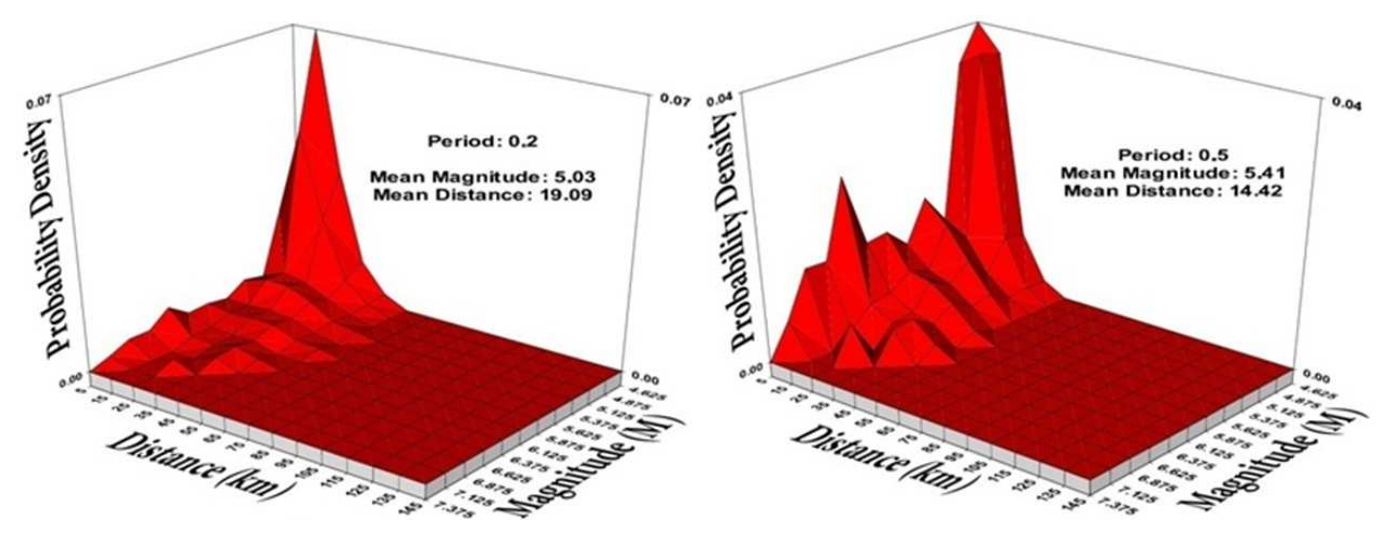



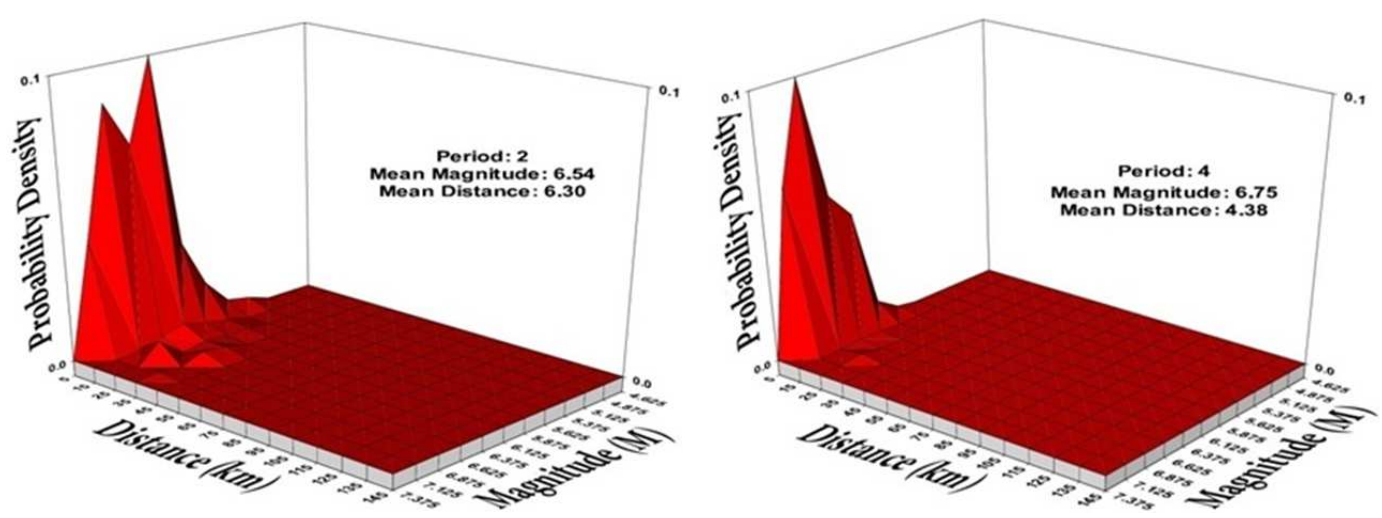

Fig. 4. Magnitude-distance deaggregation in $0.2,0.5,2$ and $4 \mathrm{~s}$, for $63 \%$ probability in $50 \mathrm{yr}$ at Karaj
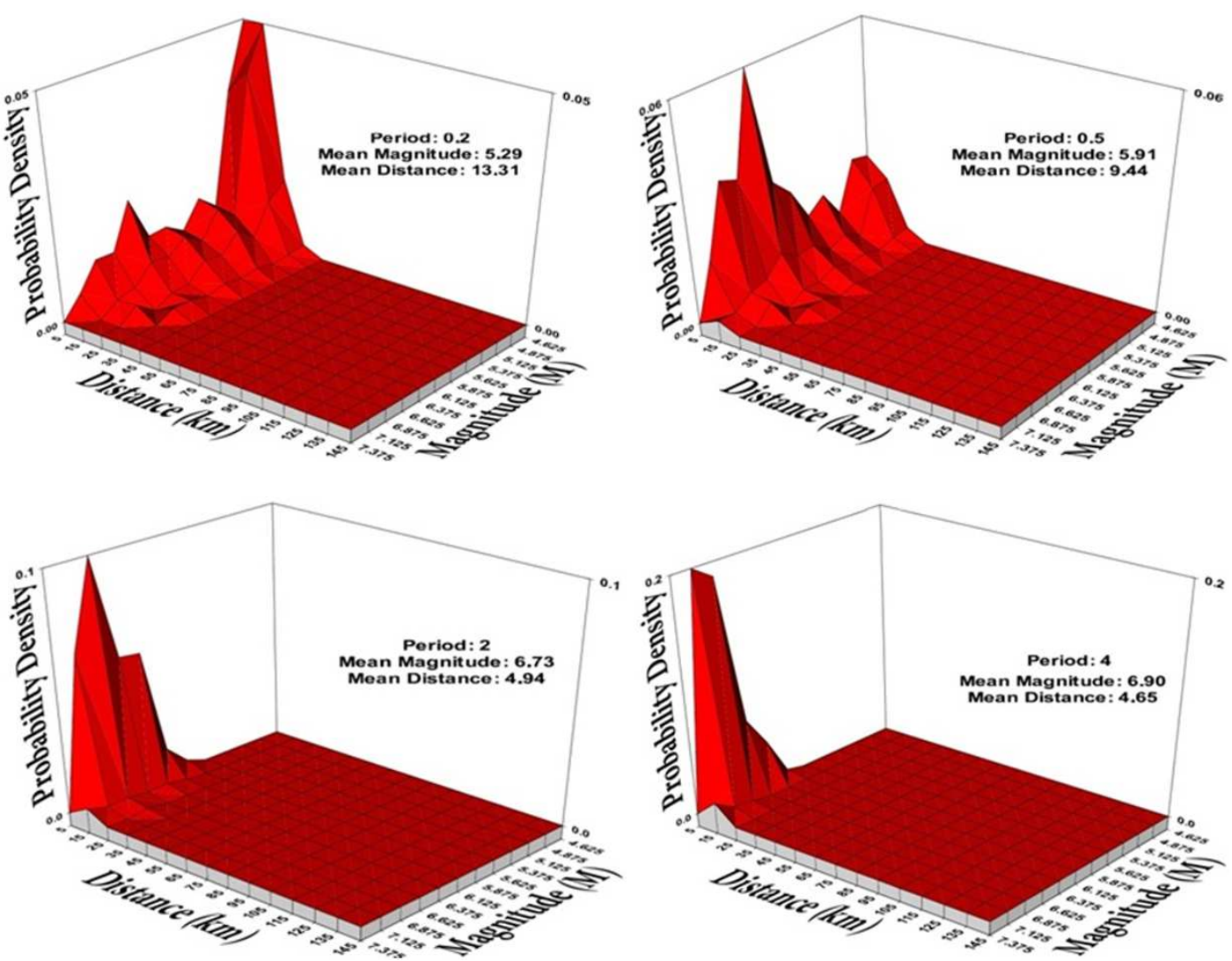

Fig. 5. Magnitude-distance deaggregation in $0.2,0.5,2$ and $4 \mathrm{~s}$, for $10 \%$ probability in $50 \mathrm{yr}$, at Karaj

It is worthwhile to mention again that a dominant event or a design earthquake is defined as a scenario which has the most contribution to the mean annual rate of exceedance of hazard from a specified level. A "dominant event" is not necessarily "the worst scenario" that can affect the site and it is obvious that because of the nature of the PSHA approach, no single event will ever be able to fully describe the seismic threat at the site. Figure 6 show the variation of mean values of $\mathrm{M}$ and $\mathrm{R}$, with spectral periods of $0.2,0.5,2$ and 4 s. The acceleration values deaggregated correspond to MRPs of 50 and $475 \mathrm{yr}$. For an MRP of $475 \mathrm{yr}$, mean magnitude and distance tend to increase with period. This trend was expected due to the fact that increasing of the mean magnitude and distance with increasing response period is a general behavior for uni-modal deaggregation plots (Harmsen et al., 1999). An analogous behavior can be observed analyzing variation of mean magnitude and distance values for an MRP of $50 \mathrm{yr}$. 


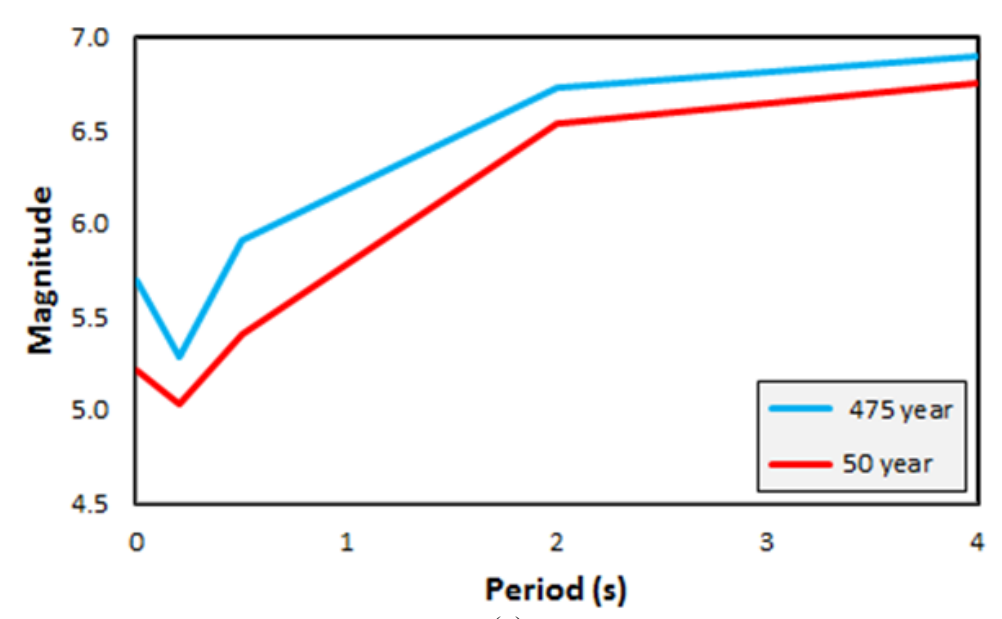

(a)

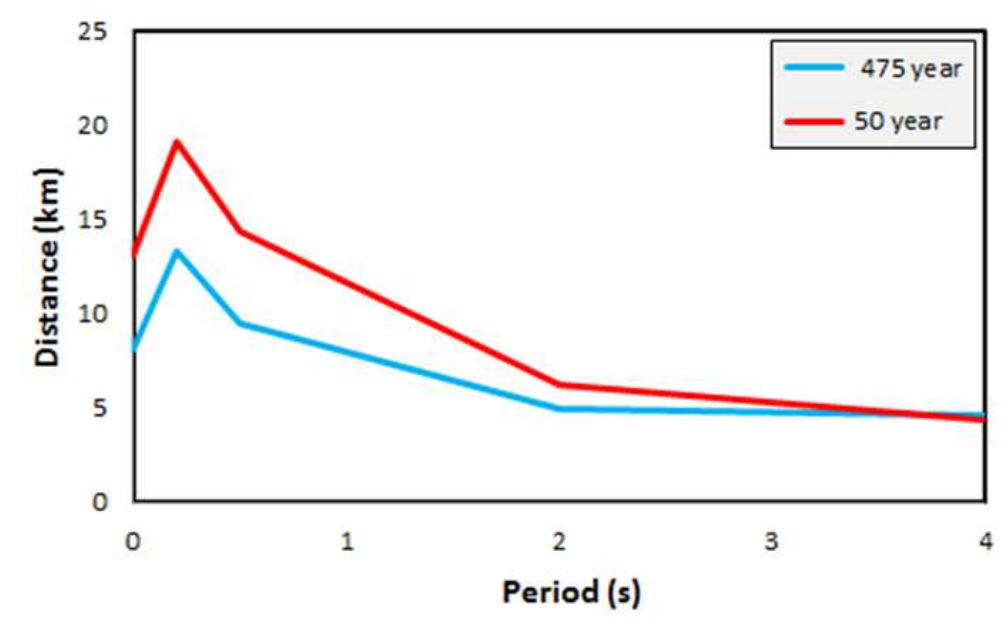

(b)

Fig. 6. Variation of mean values of M (a) and R (b) with spectral period for Karaj

For an MRP of $475 \mathrm{yr}$, variation of $\mathrm{R}$ is slightly with period and diagrams of mean distances seem close together. On the contrary, the existence of large difference between mean values of $\mathrm{R}$ for an MRP of $50 \mathrm{yr}$, especially for periods of greater than $0.5 \mathrm{~s}$ reveals that more than one seismic source contribute significantly to the site hazard for those spectral periods (Montilla et al., 2002).

\section{Conclusion}

PSHA was evaluated in order to perform seismic hazard deaggregation for Karaj city. Generally, the trend of the deaggregation results with spectral period (T) shows that the mean rate of exceeding long-period spectral accelerations is controlled by earthquakes that are larger in size and farther from the site than those dominating the PGA and short-period spectral acceleration hazard. It was also observed that the larger the MRP, the greater the contribution from closer and higher magnitude events and, as the MRP increases, both the mean values of "tend to increase. Particularly, since Karaj is located in a high seismicity region, nearby seismicity $(5 \mathrm{~km})$ has often the major contribution to the hazard. For an MRP of $50 \mathrm{yr}$, controlling earthquakes have the magnitude range between 5.0 and 6.7. Events with magnitude ranging from 5.2 to 6.9 have the most contribution to the hazard for an MRP of $475 \mathrm{yr}$ and periods longer than $4 \mathrm{~s}$, while the smaller magnitude ranging from 5.2 to 5.9 are dominant for shorter periods and PGA. Regarding deaggregation results at periods longer than 0.5 , it could be concluded that events with most contribution to corresponding hazard levels are affected by the N-Karaj seismic source. At short periods $(0.5>), \mathrm{N}$-Tehran seismic source is the most important seismic scenarios.

\section{Data and Resources}

Earthquakes catalog was searched using www.isc.com (Last accessed May 2016). 


\section{Acknowledgment}

The author thanks the Prof. AndrezijKijko for his useful guidance and scientific supports. We are also grateful to Prof. Mohsen Pourkermani for their kind helps.

In addition, special thanks to LadyShadiSalehi due to his valuable guidance in this research.

\section{Author's Contributions}

Hadi Jarahi: Developed the conceptual idea, designed the study, collected data and made the interpretation.

\section{Ethics}

This article is original and contains unpublished materials. The corresponding author confirms that he has read and approved the manuscript and there are no ethical issues involved.

\section{References}

Abdi, F., N. Mirzaei and E. Shabani, 2013. Ground-motion scenarios consistent with PSH deaggregation for Tehran, capital city of Iran. Nat. Hazards Earth Syst. Sci., 13: 679-688. DOI: 10.5194/nhess-13-679-2013

Abrahamson, N.A. and W.J. Silva, 2008. Summary of the Abrahamson and Silva NGA ground-motion relations. Earthq. Spectra, 24: 67-97. DOI: 10.1193/1.2924360

Ambraseys, N.N. and J.A. Jackson, 1998. Faulting associated with historical and recent earthquakes in the eastern Mediterranean region. Geophys. J. Int., 133: 390-406. DOI: 10.1046/j.1365-246X.1998.00508.x

Ambraseys, N.N. and C.P. Melville, 1982. A History of Persian Earthquakes. 1st Edn., Cambridge University Press, Cambridge, ISBN-10: 052124112X, pp: 236.

Barani, S., D. Spallarossa and P. Bazzuro, 2009. Disaggregation of probabilistic ground-motion hazard in Italy. B. Seismol. Soc. Am., 99: 2638-2661. DOI: $10.1785 / 0120080348$

Bazzurro, P. and C.A. Cornell, 1999. Disaggregation of seismic hazard. Bull. Seismol. Society Am., 89: 501-520.

Berberian, M., 2014. Earthquakes and Coseismic Surface Faulting on the Iranian Plateau. 1st Edn., Elsevier, Oxford, ISBN-10: 0444632972, pp: 776.

Bernreuter, D.L., 1992. Determining the controlling earthquake from probabilistic hazards for the proposed Appendix B. Lawrence Livermore National Laboratory Report UCRL-JC-111964, Livermore, California.

Boore, D.M. and G.M. Atkinson, 2008. Ground-motion prediction equations for the average horizontal component of PGA, PGV and 5\%-damped PSA at spectral periods between 0.01 and 10.0 s. Earthq. Spectra, 24: 99-138. DOI: 10.1193/1.2830434
Campbell, K.W. and Y. Bozorgnia, 2008. NGA ground motion model for the geometric mean horizontal component of PGA, PGV, PGD and 5\% damped linear elastic response spectra for periods ranging from 0.01 to 10 s. Earthq. Spectra, 24: 139-172.

DOI: $10.1193 / 1.2857546$

Chapman, M.C., 1995. A probabilistic approach for ground motion selection for engineering design. Bull. Seismol. Society Am., 85: 937-942.

Chiou, B. and R.R. Youngs, 2008. An NGA model for the average horizontal component of peak ground motion and response spectra. Earthq. Spectra, 24: 173-216. DOI: $10.1193 / 1.2894832$

Cornell, C.A., 1968. Engineering seismic risk analysis. Bull. Seismol. Society Am., 58: 1583-1606.

Cramer, C.H. and M.D. Petersen, 1996. Predominant seismic source distance and magnitude maps for Los Angeles, Orange and Ventura counties, California. Bull. Seismol. Society Am., 86: 1645-1649.

Dehghani, G.A. and J. Makris, 1983. The Gravity Field and Crustal Structure of Iran. In: Geodynamic Project Geotraverse) in Iran, Geological Survey of Iran, Rep, pp: 51-67.

Halchuk, S. and J. Adams, 2004. Deaggregation of seismic hazard for selected Canadian cities. Proceedings of the 13th World Conference on Earthquake Engineering, (CEE' 04), Vancouver, Canada, pp: 1-6.

Harmsen, S., D. Perkins and A. Frankel, 1999. Deaggregation of probabilistic ground motions in the central and eastern United States. Bull. Seismol. Society Am., 89: 1-13.

Harmsen, S., 2001. Mean and modal $\varepsilon$ in the deaggregation of probabilistic ground motion. Bull. Seismol. Society Am., 91: 1537-1552.

Harmsen, S. and A. Frankel, 2001. Geographic deaggregation of seismic hazard in the United States. Bull. Seismol. Society Am., 91: 13-26. DOI: 10.1785/0120000007

Idriss, I.M., 2008. An NGA empirical model for estimating the horizontal spectral values generated by shallow crustal earthquakes, Earthq. Spectra, 24: 217-242. DOI: $10.1193 / 1.2924362$

Jarahi, H., N. Naraghiaraghi and M. Nadalian, 2016. Short period spectral acceleration Zonation of Tehran a comparison between slip and activity rates data's. Am. J. Geosci. Sci.

JICA and CEST, 2000. The study on seismic microzoning of the greater Tehran area in the islamic republic of Iran, Final report. Japan International Cooperation Agency and Centre for Earthquake and Environmental Studies of Tehran, Tehran Municipality.

Kijko, A., 2010. Seismic hazard assessment for selected area. Hazard Area documentation MATLAB.doc. 
Kijko, A., 2012. Seismic Hazard. In: Encyclopedia of Solid Earth Geophysics, Gupta H. (Ed.), Springer, pp: 1107-1121.

Mirzaei, N., M. Gao and Y.T. Chen, 1998. Seismic source regionalization for seismic zoning of Iran: Major seismotectonic provinces. J. Earthquake Predict. Res., 7: 465-495.

McGuire, R.K., 1995. Probabilistic seismic hazard analysis and design earthquakes: Closing the loop. Bull. Seismol. Society Am., 85: 1275-1284.

Montilla, J.A., C.L. Casado and J.H. Romero, 2002. Deaggregation in magnitude, distance and azimuth in the South and West of the Iberian Peninsula. Bull. Seismol. Society Am., 92: 2177-2185. DOI: $10.1785 / 0120010295$

Ni, S.H., 2012. Design earthquakes based on probabilistic seismic hazard analysis. PhD Theses, University of Waterloo, Ontario, Canada.

Nowroozi, A.A., 1985. Empirical relations between magnitudes and fault parameters for earthquakes in Iran. Bull Seismol. Society Am., 75: 1327-1338.

Shabani, E. and N. Mirzaei, 2007. Probabilistic Seismic hazard assessment of the Kermanshah-Sanandaj region of Western Iran. Earthq. Spectra, 23: 175-197. DOI: $10.1193 / 1.2431210$

Shi, Z., J. Yan and M. Gao, 1992. Research on the principle and methodology of seismic zonationresults of the trials in North China. Acta Seismol. Sinca, 5: 305-314. DOI: 10.1007/BF02651697
Shoja-Taheri, J., S. Naserieh and G. Hadi, 2010. A test of the applicability of NGA models to the strong ground-motion data in the Iranian Plateau. J. Earthq. Eng., 14: 278-292.

DOI: $10.1080 / 13632460903086051$

Sokolov, V.Y., 2000. Hazard-consistent ground motions: Generation on the basis of uniform hazard Fourier spectra. Bull. Seismol. Society Am., 90: 1010-1027. DOI: $10.1785 / 0119990107$

Sousa, M.L. and A.C. Costa, 2009. Ground motion scenarios consistent with probabilistic seismic hazard disaggregation analysis. Application to Mainland Portugal. Bull. Earthq. Eng., 7: 127-147. DOI: $10.1007 / \mathrm{s} 10518-008-9088-\mathrm{z}$

Wells, D.L. and K.J. Coppersmith, 1994. New empirical relationships among magnitude, rupture length, rupture width, rupture area and surface displacement. Bull. Seismol. Society Am., 84: 974-1002.

Ye, H., G. Chen and Q. Zhou, 1995. Study on the intraplate potential seismic sources for seismic zonation and engineering seismic hazard analysis in continental areas. Continental Earthquakes, IASPEI publication series for the IDNDR.

Zare, M., 1995. Relationships for Magnitude, intensity and pike horizontal acceleration base on Iranian Earthquakes. J. Seismol. Eng. Earthquake Res., 6: 12-14. 